\title{
Aprender del pasado: la delgada e jinvisible! línea entre las políticas de seguridad de Andrés Pastrana y Álvaro Uribe*
}

\author{
Learn from the past: the thin (invisible) \\ line between security policies during the \\ administrations of Andrés Pastrana and Álvaro \\ Uribe
}

\author{
Camilo Manchola Castillo* \\ Beatriz Helena Tiusabá Gómez ${ }^{* * *}$
}

Fecha de recepción: 31/07/2017

Fecha de aceptación: 25/09/2017

\section{Resumen.}

* Este artículo es producto del proyecto de investigación INV-EES-2095 «La política exterior norteamericana (1989 - 2016): la burocratización de una política pública», financiado por la Vicerrectoría de investigaciones de la Universidad Militar Nueva Granada

** Candidato a PhD de la Universidad de Brasilia. Coordinador y profesor de la Especialización Lato Sensu en Bioética de la Cátedra UNESCO de Bioética de la Universidad de Brasilia. Magíster en Educación y Profesional en Relaciones Internacionales y Estudios políticos de la Universidad Militar Nueva Granada. Estudios de Maestría en Ciencias Sociales en la Universidad de Helsinki.camilomanchola@gmail.com

*** Magíster en Relaciones y Negocios Internacionales de la Universidad Militar Nueva Granada. Politóloga de la Universidad de Los Andes. Docente de tiempo completo e investigadora de la Universidad Militar Nueva Granada. beatriz.tiusaba@unimilitar.edu.co 
Las guerras que los Estados Unidos de América han emprendido en contra de amenazas internacionales, se han justificado en «prácticas discursivas» de sus líderes, y las políticas de seguridad que se encarnan en las mismas. Se impone la necesidad de estudiar la relación entre estas y las políticas de seguridad de otros actores del sistema internacional. Este trabajo destaca la importancia que tuvieron tales prácticas en la securitización inducida por los Estados Unidos de América de la política de seguridad en Colombia, entre 1998 y 2006, durante los gobiernos Pastrana y Uribe. Se concluye que las políticas de seguridad detrás de estas administraciones se inscribieron en los discursos securitizadores de las administraciones estadounidenses. Los niveles de securitización en el discurso variaron solo en intensidad.

\section{Palabras clave}

Política de defensa y seguridad democrática, Plan Colombia, Teoría de la securitización.

\section{Abstract.}

Wars conducted by the USA against international threats, have been justified through "discursive practices" from their leaders, and security policies that are embodied in the same ones. It is necessary to study the relation between these discursive practices and security policies of other actors of the international system. This paper emphasises the importance of discursive practices for the securitization of Colombia's security policy, induced by the U.S.A between 1998 and 2006, during the administrations of presidents Pastrana and Uribe. We conclude that security policies behind these administrations were particularly enrolled in the context of the securitizing discourses of American administrations. Securitizing levels in discourse varied only in intensity. 


\section{Keywords}

Defense and Democratic Security Policy, Plan Colombia, Securitization Theory.

\section{Introducción}

Para empezar es necesario hacer un recuento de las políticas de seguridad que, tanto los Estados Unidos de América como Colombia, implementaron dentro del período de tiempo que se analizará -esto es, 1998 a 2006-; pues como se verá, gracias a ellas se comprenderá cómo influyó la «securitización estadounidense» sobre las políticas de seguridad nacional colombianas, y más allá de eso, por qué se argumenta que, contrario a lo que se piensa, la Política de Seguridad Democrática (Presidencia de la República de Colombia, 2003) y el Plan Colombia reflejan los mismos objetivos y propósitos, aunque ocultos por estrategias discursivas y del lenguaje inteligentemente pensadas y puestas en práctica -reveladas por el concepto de la securitización, y explicadas por la teoría realista post-estructuralista.

Así las cosas, se comenzará por hablar de las políticas de seguridad -y obviamente, del contexto dentro del que ellas se elaboraronde Bill Clinton y George W. Bush (Bush, de aquí en adelante), para luego pasar a las de Andrés Pastrana y Álvaro Uribe; se debe aclarar que mientras se hace esa revisión, se trabajará en demostrar su interrelación. Lo anterior, teniendo en cuenta las teorías de las relaciones internacionales que más se ajustan a esta relación e interrelación de los discursos y las políticas, tanto norteamericanas como colombianas; es decir, la teoría realista y la teoría constructivista, de la que se desprende la securitización.

Mediante la teoría de la securitización, se explicará cómo las políticas estadounidenses y colombianas ejecutadas durante los Gobiernos de Clinton-Bush y Pastrana-Uribe, convergen con los tres 
elementos principales de esta misma; es decir, el actor securitizador, el objeto referente y la audiencia y permiten analizar la relación existente entre las mismas. Así pues, se concluye reafirmando la principal hipótesis del artículo; la innegable influencia de las políticas de seguridad de los Estados Unidos de América durante los gobiernos de Clinton y Bush sobre la implementación del Plan Colombia y la Politica de Seguridad Demcrática en los gobiernos de Pastrana y Uribe, como una continuidad de los objetivos propuestos en cuanto a seguridad se refiere.

\section{Las políticas de seguridad estadounidenses}

Bill Clinton hizo importantes cambios al abordaje de la seguridad de Estados Unidos de América, pues dio al tema económico una relevancia que hasta el momento no había tenido. De hecho, se reconoce a la inclusión de ese factor económico al Consejo Nacional de Defensa -principal órgano de consulta del presidente- como un aporte suyo, por medio del llamado del Secretario del Tesoro y del jefe del Consejo Económico de la Casa Blanca al Consejo Nacional de Defensa (Worley, 2008).

Sin embargo, a Clinton también se le culpa de no propiciar un acercamiento necesario entre el Departamento de Estado y el de Defensa; algo que se le reconoce a Bush, sobretodo, con la designación de Colin Powell y Donald Rumsfeld, como Secretarios de Estado y de Defensa, respectivamente.

Habría que destacar que, así como existió una continuidad en cuestiones de seguridad entre Pastrana y Uribe -como se demostrará más adelante-, también resulta que en el caso de los Estados Unidos de América pasó algo muy similar entre Clinton y Bush, pues tal como lo dice Hendrickson (2008): «aunque los presidentes Bill Clinton y George W. Bush son de partidos políticos diferentes y estuvieron en el cargo durante circunstancias estratégicas muy di- 
ferentes, ambos usaron la fuerza en Iraq y contra Osama Bin Laden durante sus administraciones». En este respecto, también conviene mencionar las repetitivas declaraciones del presidente Clinton, en las que se apoyaron las intervenciones de Bush en Iraq, dando un espaldarazo a su política de seguridad; de hecho, conviene recordar lo dicho por él en 2004: «Yo he defendido reiteradamente al presidente Bush contra la izquierda en Iraq» (CNN, 2004).

En congruencia con este contexto, sería preciso revisar las políticas de seguridad formuladas por Clinton (teniendo en mente que entre sus dos períodos presidenciales hubo cambios sustanciales con respecto al tema anteriormente mencionado). Conviene decir que los historiadores documentan, en primera medida, una ruptura importante entre lo que el presidente George H. W. Bush tomó como sus políticas de seguridad más relevantes -Reporte de Seguridad Nacional (National Security Review) y Directiva de Seguridad Nacional (National Security Directive)-, y lo que emprendió Clinton -Directiva de Revisión Presidencial (Presidential Review Directive) y Directiva Presidencial 2 (Presidential Directive 2)-, por cuanto este último, al ser el primer presidente de la post-Guerra Fría, dio un nuevo rumbo a los asuntos de seguridad y política exterior (The White House, 1998).

En segunda medida, también hay que mencionar que los académicos, además, dan cuenta que el segundo período de Clinton significó un cambio, por cuanto fue en ese momento, cuando la cuestión económica se contempla dentro de los elementos a ser considerados en el abordaje de las políticas de seguridad. Es importante aquí destacar las declaraciones de Clinton a propósito de la firma del Plan Colombia, pues son ellas una muestra perfecta de la alineación de la economía con la seguridad dentro de la política exterior y de seguridad de este presidente; de hecho, Clinton afirmó que el propósito del Plan Colombia era: «hacer énfasis en el apoyo america- 
no a los esfuerzos colombianos por buscar la paz, luchar contra las drogas ilícitas, construir la economía y profundizar la democracia» (Carrigan, 2000).

Como se ve, Clinton siempre fue claro en que, si bien, el Plan Colombia tenía como objeto luchar contra las drogas y construir la paz, su trasfondo era fortalecer la economía y la democracia, todo lo cual es para la clase política norteamericana completamente imprescindible, pues hace parte de su imaginario e identidad. De hecho, la doctrina de "El Destino Manifiesto" (Manifest Destiny) es el perfecto reflejo, pues más allá de servir de justificación para anexiones territoriales, ha sido decisivo para que los americanos creyeran en que su modelo estatal y social debía ser implantado en todo el mundo, tal como lo reconoce Lawrence Davidson (2005), cuando afirma que: «los Estados Unidos de América (eran vistos) como la punta de lanza del destino manifiesto occidental», y que «eso significaba que el destino manifiesto occidental debía ser dirigido por el avance de la cultura americana».

Ahora, respecto al contexto y definición de las políticas de seguridad de Bush en su primer período, hay que acotar -como ya se ha dicho- que más que una ruptura con la anterior administración, las políticas de seguridad de este significaron la continuidad de las emprendidas por Clinton, pues sus elementos centrales -lucha contra las drogas, guerra contra la insurgencia, preponderancia de los intereses económicos dentro de la esfera de la seguridad- se mantuvieron; es decir, que contrario a lo que muchos opinan, dichas políticas fueron exacerbadas - mas no originadas- por los atentados del 11 de septiembre de 2001 (Badey, 2000; Lee, 2001; Guida, 2010).

A propósito de estos atentados, es momento de documentar su ya ampliamente debatido papel, punto de inflexión de la historia no solo americana sino mundial, pues tiene que ver con la construcción de las políticas de seguridad estadounidenses, y en consecuencia 
(para los efectos metodológicos de este artículo), colombianas, todas ellas enmarcadas dentro de lo que se llamaron las Directivas Presidenciales de Seguridad Nacional (National Security Presidential Directives) y las Directivas Presidenciales de Seguridad de la Patria (Homeland Security Presidential Directives) $)^{1}$, lo que a todas luces constituyen pruebas fehacientes del enfoque militarista que Bush proporcionó a la seguridad -no es gratuito que este presidente tuviera un Consejo de Seguridad Nacional (National Security Council)2 débil, por cuanto era más fácil controlarlo y manipularlo, de esta manera trasladando sus funciones al Pentágono (Worley, 2008.).

Es importante recalcar la afirmación según la cual dichos atentados sólo significaron la exacerbación de las políticas de seguridad de Clinton, porque, aunque el discurso cambió -ahora introduciendo términos como «terrorismo, eje del mal, guerra contra el terror, estados canallas»-, las prácticas usadas siguieron siendo las mismas; prueba de ello, verbigracia, es consistente en que el militarista Plan Colombia fue ideado y puesto en práctica antes de los citados atentados.

La que sí tuvo, sin duda alguna, una conexión enorme con esos atentados fue la "Política de Seguridad Democrática"; en efecto, intrínsecamente en la misma se reconocen las consecuencias de tales atentados como soportes de ella, cuando se constata que uno de

1 Las directivas presidenciales, mejor conocidas como Directivas Presidenciales de Decisión (PDD, por sus siglas en inglés) son una forma de orden ejecutiva firmada por el presidente de los Estados Unidos de América con la asesoría y conocimiento del Consejo de Seguridad Nacional. Como instrumento de seguridad nacional que es, la PDD articula las políticas del ejecutivo, vela por la efectividad y fortaleza de la ley, y a través de los periodos de los distintos presidentes, va tomando diferentes nombres o títulos, según las posturas de cada uno. Para ampliar esta información, ver RELYEA, Harold. CRS Report for Congress: Presidential Directives, Background and Overview. 23 de abril de 2007. Pp. 2 a 5.

2 El Consejo de Seguridad Nacional (NSC, por sus siglas en inglés) es el principal foro para la consideración por parte del presidente de los asuntos de política exterior y las cuestiones de seguridad nacional de los Estados Unidos de América. De acuerdo a las directivas de revisión política, el NSC reúne hechos y puntos de vista de agencias gubernamentales, conduce análisis, determina alternativas y presenta al presidente alternativas políticas para la toma de decisiones. Las decisiones presidenciales son anunciadas por medio de directivas. Para ampliar esta información, ver http://www.fas.org/irp/offdocs/direct.htm. Consultado el 08 de marzo de 2016. 
sus mayores argumentos para justificar su lucha contra los grupos ilegales, y su deseo de elevar a la seguridad como origen y fin de la democracia, son los pronunciamientos expresados como producto de ese evento -véanse la Resolución 1373 del 28 de septiembre de 2001 del Consejo de Seguridad de las Naciones Unidas y la Convención Interamericana contra el Terrorismo del 3 de junio de 2002 (Presidencia de la República de Colombia, 2003).

Luego de haber hecho esta somera mención del 11 de septiembre, constatando su relación con las políticas de seguridad estadounidenses y colombianas, es momento de revisar más de cerca las Directivas Presidenciales de Seguridad Nacional (National Security Presidential Directives) y las Directivas Presidenciales de Seguridad de la Patria (Homeland Security Presidential Directives) -especialmente la que se titula Política Estratégica de Seguridad Nacional (National Security Strategy Policy). Al hacerlo, es posible evidenciar diferentes cuestiones: primero, que se otorga un lugar muy relevante a la unilateralidad en el uso de la fuerza; segundo, que se da especial preponderancia a la guerra preventiva; y tercero, que las dos anteriores pueden ser argumentos válidos para el desmantelamiento de las estructuras gubernamentales de algunos gobiernos; algo que, claramente, es extraordinariamente coincidente -como se verá más adelante- con la Política de Seguridad Democrática del presidente Álvaro Uribe.

En cuanto a lo primero, es evidente en esta directiva que los norteamericanos ven no sólo como un deber, sino como un derecho, el uso de su fuerza para la salvaguarda de sus intereses, obviamente, escudándose en la supuesta obligación de velar por la seguridad internacional. Lo anterior, por su parte, se relaciona perfectamente con la validez que le imprimen a la guerra preventiva, elevándola al nivel de un instrumento legítimo y moral de la política exterior estadounidense, como lo observaría Arthur Schlesinger Jr. (2002) y Octavio Caro (2006). 


\section{Las políticas de seguridad colombianas}

Una vez revisados, los principales atributos de las políticas de seguridad de los presidentes estadounidenses -a ras de piso-, es momento de hacer lo propio con los mandatarios colombianos; eso, con el propósito de dejar manifiesta la alineación existente entre ambas políticas, y de esa manera, ir preparando el abordaje del análisis de los discursos de los mismos presidentes. Naturalmente, el primer paso que se dará, será el análisis de las políticas del presidente Pastrana, para luego entrar a revisar las del presidente Uribe.

Andrés Pastrana, fue el artifice del Plan Colombia, pero además de políticas supuestamente basadas en la resolución del conflicto colombiano de una manera negociada; en efecto, fueron comunes sus pronunciamientos argumentando que nadie podía oponerse a aquel plan porque un $70 \%$ del mismo estaba destinado a la inversión social, y que Washington tenía muy claro que una solución militar al conflicto era inviable e irreal. En cuanto a las negociaciones (del Plan), es preciso recordar que se llevaron a cabo dentro de un ambiente de escepticismo, en el que las opiniones a favor y en contra no se hicieron esperar, y dieron cuenta de su peligrosidad, pero también de la necesidad para buscar una solución a la situación colombiana. Declaraciones del excanciller Rodrigo Pardo así lo demostraron, en el sentido de que el Plan Colombia significaba "lograr mucho o perder mucho", y que era un riesgo que había que tomar (BBCMundo.com).

Luego de las fracasadas negociaciones, el Plan fue aprobado en el año 2000, y con él se buscaba fortalecer al Ejército -no a la Policía, como había ocurrido con la ayuda americana en el período 19891990-. Como se ve, algo completamente direccionado hacia el énfasis en un abordaje militarista del conflicto (Tokatlián, 2004). De hecho, el mismo presidente Pastrana puso en entredicho sus políticas de negociación, al declarar que: "No todo comenzó con Uribe” (El 
Nuevo Siglo), haciendo alusión a que durante su gobierno, hubo una gran modernización de las capacidades militares del país.

Es conveniente rescatar en este punto lo escrito por Pastrana, en el texto "Retroceder en el tiempo es una opción", pues en él demuestra que el ex-presidente tuvo una fuerte influencia en lo que Uribe enfatizó como un triunfo sólo suyo: "Hoy, cuando a Colombia le plantea su Presidente la posibilidad de quedarse en el poder quién sabe hasta cuándo, es hora de que el país se atreva a acordarse de que antes de estos dos últimos gobiernos, aún antes del Caguán, hubo hechos y personas que definieron el rumbo de Álvaro Uribe" (Pastrana, 2010).

Para mayor precisión, hay que denotar que el Plan Colombia fue concebido como un paquete de ayuda por un total de US\$ 1319 millones -aprobado en junio 30 de 2000-, de los cuales se contaba con fondos no sólo para Colombia, sino para otros países andinos y agencias americanas relacionadas con la lucha contra las drogas y el incentivo del imperio de la ley. Del total de ayuda, se destinó finalmente para Colombia un 65\%, mientras para otros países andinos (se incluye acá a Ecuador, Perú, Bolivia, Venezuela, Panamá, e incluso, Brasil) un 14\%, y para las agencias un $17 \%$ (Cipcol.org). ${ }^{3}$

Cabe aclarar que la propuesta de la administración Clinton suponía dar a Colombia un $81 \%$, que naturalmente, al final, no fue aprobado, pues el Congreso estadounidense concebía el problema de las drogas como un asunto que no competía exclusivamente a Colombia, sino que además tenía un trasfondo social importante. Del total de ayuda dada a Colombia, un $80 \%$ correspondió a ayuda

3 Esta es una iniciativa del Center for International Policy's Latin America Demilitarization Project, que incluye el CIP's Colombia Program, el Latin America Working Group Education Fund, y la oficina en Washington sobre Latino América, todos ellos constituyentes de la base de datos de monitoreo y asistencia militar Just the Facts. El The Center for International Policy, fue fundado en 1975, en tiempos de la Guerra de Vietnam, por ex-diplomáticos y activistas pacíficos. La mezcla entre quienes están en el gobierno y quienes están fuera de él, por decisión propia, ha formado tanto la metodología como la agenda de The Center for International Policy. 
militar/policial y un $20 \%$ a asistencia económica -de manera más específica, se consideraron 5 categorías dentro del Plan, a saber: apoyo antinarcóticos (incluyendo fumigación aérea), interdicción, policía nacional colombiana, desarrollo alternativo y aumento de las capacidades gubernamentales-; dos extensiones al Plan se dieron bajo el gobierno de George W. Bush, en 2001 -por un valor de US\$ 380 millones- y en 2004 -por un valor de US\$ 727 millones-; estas extensiones tuvieron el objetivo, dentro del marco de la lucha contra el terrorismo mundial, de procurar por la reducción de las guerrillas en el país -fue notabilísimo detalle cómo entonces se les empezó a designar narco-terroristas, de acuerdo al discurso oficial- (Cipcol.org).

Antes de terminar con el Plan Colombia es importante decir que este enumeraba diez estrategias a su servicio; a saber: 1) Económica; 2) Fiscal y financiera; 3) Acuerdo de Paz negociado con la guerrilla con base en integridad territorial, democracia y DD. HH., y lucha contra el narcotráfico; 4) Reestructuración y modernización de FF. MM. y Policía; 5) Fortalecimiento del Poder Judicial; 6) Estrategia antinarcóticos en asociación con la Comunidad Internacional; 7) Desarrollo alternativo campesino con protección ambiental; 8) Participación social; 9) Servicios de salud y educación universales; y 10) Impulso al principio de corresponsabilidad, acción integrada y tratamiento equilibrado para el problema de la droga.

Conviene explicar cada una de las estrategias del Plan. En cuanto a la económica, el texto preveía que el Plan generara empleo, fortaleciera la capacidad del Estado para recaudar impuestos, al ofrecer una alternativa para erradicar el narcotráfico. Así mismo, el fortalecimiento del comercio internacional, y la firma de tratados internacionales.

En lo que se refería a la fiscal y financiera, la idea era que el Plan permitiera la adopción de medidas severas de austeridad y ajuste, que llevaran a la recuperación de la imagen de Colombia ante los orga- 
nismos internacionales financieros, pero que también estuvieran lo suficientemente bien diseñadas como para limitar el impacto social negativo de esta clase de medidas económicas. En relación con la estrategia de paz, el Plan propendía por alcanzar acuerdos con las guerrillas -específicamente, las FARC y el ELN-, con base en "integridad territorial, democracia y derechos humanos", por medio de la creación de un área desmilitarizada o "de distensión", que contara con la participación de la comunidad internacional, en las áreas diplomática y financiera.

En cuanto a la estrategia de defensa nacional, el Plan suponía la modernización y reestructuración de las Fuerzas Militares y la Policía, de tal forma que estos pudieran recuperar el Estado de derecho y garantizar la seguridad de los colombianos. La estrategia judicial y de derechos humanos, por su parte, tenía como objetivo reafirmar el Estado de derecho, asegurar justicia igualitaria e imparcial para todos, promover las reformas al estamento militar y policial, y condenar a narcotraficantes y demás delincuentes.

La de antinarcóticos, por su lado, promovía la concientización mundial de que el fenómeno del tráfico de drogas es corresponsabilidad de todas las naciones, abogaba por impedir el flujo de recursos originarios de este fenómeno hacia las guerrillas, y priorizar la protección de los derechos humanos sobre cualquier esfuerzo contra el tráfico de drogas. Además, esta estrategia; la más extensa de todas en el documento, citaba como sus elementos básicos: "1). Consolidar el control sobre el espacio aéreo nacional por todos los medios disponibles, 2). Fortalecer los esfuerzos conjuntos entre Colombia y Estados Unidos y aumentar el número de tropas empleadas en operaciones, 3). Aumentar la movilidad en las selvas, con énfasis en operaciones aéreas y fluviales, 4). Fortalecer y aumentar el uso de operaciones conjuntas de seguridad durante tareas de fumigación y erradicación, y 5). Apoyar las nuevas estrategias del Programa de 
Naciones Unidas para Fiscalización Internacional de Drogas, en las pruebas y desarrollo de agentes de control biológico ambientalmente seguros, con el fin de encontrar nuevas tecnologías de erradicación” (Presidencia de la República de Colombia, 2001).

La séptima estrategia, o de desarrollo alternativo, contemplaba la implementación de esquemas agropecuarios rentables para los campesinos, de tal manera que el narcotráfico ya no fuera la única opción para generar ingresos. La octava, o estrategia social, y la novena, o de desarrollo humano, estaban absolutamente relacionadas, y apuntaban a la concientización colectiva -que incluyera lucha contra la corrupción, compromiso social, etc.- y a la garantía de los servicios de salud y educación para los sectores más vulnerables. La décima y última estrategia, estaba naturalmente dirigida a confirmar los "principios de corresponsabilidad, acción integrada y tratamiento equilibrado para el problema de la droga” (Presidencia de la República de Colombia, 2001) a nivel internacional.

Asimismo el Plan "Contiene una descripción de la situación política, económica, social y militar del país. Describe la falta de consolidación del Estado Nacional e identifica entre sus múltiples explicaciones a la violencia y la corrupción alimentadas por el narcotráfico, como factores determinantes que impiden o frustran los esfuerzos para la construcción exitosa de un estado moderno" (laondadigital. com). Por último, se enfatiza que este Plan "Define la búsqueda de la paz y la defensa de las instituciones democráticas como objetivos, y a las negociaciones con los grupos insurgentes como el núcleo de su estrategia” (laondadigital, Íbid.).

Más allá de este Plan y de las políticas de negociación, Pastrana fue autor de la cuestionada, y declarada inconstitucional, ley $684 \mathrm{de}$ 2001 -o ley por medio de la cual se declaraba el Estado de Sitio-, paquete legislativo por el cual se daban poderes extraordinarios al presidente de la República y a las Fuerzas Armadas, para controlar el 
orden público, al mismo tiempo que se restaban funciones independientes e importantes a la Fiscalía General de la Nación, y por el cual se creaba lo que dio en llamarse el poder nacional (Carvajal, 2008), elemento que más adelante será objeto de análisis, cuando la teoría de la securitización así como la teoría realista post-estructuralista sean abordadas.

Por su parte Álvaro Uribe Vélez, además de ser el responsable de la puesta en marcha de la Política de Seguridad Democrática, lo fue también de otra ley declarada inconstitucional, directamente relacionada con la seguridad, denominada Estatuto Antiterrorista; considerado como un intento parecido al de Pastrana para controlar el orden público, pero con un agravante: la pretensión de cambiar la Constitución Nacional, para poder limitar los derechos de libre movilización e intimidad de los ciudadanos (Carvajal, 2008).

En cuanto a la Política de Seguridad Democrática, hay que enfatizar que constituye de lejos la continuación del llamado Plan Colombia -valga aclararlo, por medio de la Iniciativa Antidroga Andina (ACI, por sus siglas en inglés) (Veillete, 2005)-, pues se financió gracias a este mismo (Instituto de Ciencia Política), y estuvo directamente relacionada con sus objetivos, propósitos y metas. En efecto, si se revisa el contenido de esta política y del Plan, se confirmará fácilmente que la estrategia de lucha contra la guerrilla y el narcotráfico, está completamente justificada por sus alcances de desarrollo económico, institucional y democrático (International Crisis Group, 2008).

Definida como: "una política de Estado de largo plazo, que se desarrollará en coordinación con todas las entidades del Gobierno y las demás ramas del poder", la Política de Seguridad Democrática fue desarrollada en y desde 2003, y trazó seis líneas de acción, que fueron: coordinar la acción del Estado, fortalecer las instituciones del Estado, consolidar el control del territorio nacional, proteger a 
los ciudadanos y la infraestructura de la nación, cooperar para la seguridad de todos, comunicar las políticas y acciones del Estado. Debe especificarse en este punto que al revisar el documento de la política, llama la atención encontrar que el Plan Colombia, principal fuente de financiación de ella, es apenas mencionado en el cuadro de responsabilidades -no es abordado en el apartado de financiación-.

Es preciso dar una mayor explicación de esta política, y para ello es importante identificar sus raíces, pues al mismo tiempo se convirtieron en las determinantes de las citadas líneas de acción (Tiusabá, 2004): “1) La Política de Defensa y Seguridad Democrática de septiembre de 2002; 2) El capítulo 1 del Plan Nacional de Desarrollo, que lleva como título Brindar Seguridad Democrática y 3) La Seguridad de la Solidaridad: Política de Defensa y Seguridad Democrática".

Una vez aclarado esto, es importante ir sobre cada una de las líneas de acción descritas, diciendo primero que responden a también seis amenazas: el terrorismo, las drogas ilícitas, las finanzas ilícitas, el tráfico de armas, municiones y explosivos, el secuestro y la extorsión, $\mathrm{y}$, por último, el homicidio. La primera es relativa a los niveles de decisión y coordinación que deben observarse cuando de decidir sobre temas de seguridad y defensa nacional se trate, y por tanto, en ella se nombran al Consejo de Seguridad y Defensa Nacional, los ministerios, la Fuerza Pública, etc., y más allá de eso, se estipula que a cada una de esas instancias se asignarán tareas y herramientas de evaluación que permitan determinar resultados y prospectivas.

La segunda, por su parte, tiene que ver con el fortalecimiento de la institucionalidad, que constituiría el eje del gobierno del presidente Uribe Vélez en sus decires, y se pretendió base fundamental de la consecuencia de la Política de Seguridad Democrática: la Política de Consolidación de la Seguridad Democrática. Además, en esta línea se explica que ese fortalecimiento se alcanzará una vez haya una 
presencia permanente no sólo de la Fuerza Pública, sino de todas las instituciones del Estado -esto es, Fiscalía, Ministerio Público, entre otras- en todos los rincones del territorio nacional.

La tercera está directamente relacionada con lo anterior, pues se refiere a la consolidación del control territorial, paso anterior a la presencia de las instituciones estatales en cualquier punto de la geografía nacional. Así, tal como lo dice la Política, el objetivo de esa línea de acción es, luego de desarticular las organizaciones armadas ilegales "proteger a la población y restablecer la autoridad de las instituciones democráticas” (Presidencia de la República, 2000). Es básico enfatizar que dentro de esta línea también se preveía la eliminación del negocio de las drogas ilícitas.

La cuarta línea tiene que ver con garantizar el cumplimiento de los derechos fundamentales de los ciudadanos -contrarrestando el problema del desplazamiento, la desmovilización, el reclutamiento forzado de la población infantil, el secuestro y la extorsión-, así como con proteger los bienes de la nación -básicamente la infraestructura portuaria, aeroportuaria, petrolera, etc.-. La quinta línea relaciona los conceptos de solidaridad y seguridad, pues establece que los ciudadanos serán un instrumento esencial para la prevención de ataques terroristas, acciones delincuenciales, y problemas relativos a todo ello. Así, esta línea pretendía la creación de programas de recompensas e informantes en zonas rurales y urbanas. La sexta línea, por último, preveía la divulgación y comunicación de lo consignado en la Política, así como de sus resultados; como punto importante, en este acapite se hace expresa la solicitud a los medios de comunicación para que no transmitan actos terroristas en directo.

Para cerrar este apartado, es conveniente hablar de los resultados y alcances que las políticas mencionadas tuvieron para sus administraciones y, en general, para la realidad política tanto de Colombia como de Estados Unidos de América. Se debe comenzar por decir 
que, como ha sido manifestado, las políticas demuestran un fuerte componente de continuidad -tanto en el caso americano como colombiano-, pero más allá, que ellas han tenido consecuencias diametralmente opuestas, en cuanto a sus logros y las percepciones que han generado en la población.

Así, mientras la Política de Seguridad Democrática significó para el presidente Uribe uno de sus más importantes argumentos para ser reelegido en 2006, el Plan Colombia, y en general, la política de seguridad de George W. Bush es criticada y tiene niveles de aceptación bajos. Y es que son muchos los que han entendido que el estilo de Bush es uno lleno de contrastes y, más allá de eso, contradictorio, lo que ha resultado completamente evidente para sus compatriotas (Moens, 2004).

Es importante traer a colación aquí los resultados de la Política de Seguridad Democrática, y como se ha explicado, de su resultado, el Plan Colombia, pues esto permitirá entender el porqué de esas consecuencias diametralmente opuestas. Es esencial aclarar que sólo se mostrarán resultados de lo acontecido durante el primer gobierno de Uribe, por cuanto antes no hubo evaluaciones de resultados disponibles (naturalmente, porque el Plan empezó en 2000 y Pastrana terminó su gobierno en 2002).

Así, de acuerdo a las cifras oficiales, la Política de Seguridad Democrática -que como ya se ha dicho, recibió buena parte de su financiación del Plan Colombia, y conserva los objetivos y metas de ese Plan-, según la información oficial, ha logrado mucho en recuperación del territorio, disminución en el número de secuestros, extorsiones, asesinatos y número de hectáreas de droga sembradas (Ministerio de Defensa Nacional-Presidencia de la República de Colombia, 2004).

Sin embargo, informes de entidades internacionales, como el Reporte Mundial sobre las Drogas 2009 (World Drug Report 2009, 
en inglés) de la Oficina de las Naciones Unidas para las Drogas y el Crimen (United Nations Office on Drugs and Crime, en inglés), o El Reporte Mundial sobre las Drogas 2009: una respuesta del Consorcio Internacional sobre Política contra las drogas (The 2009 World Drug Report: A Response From the International Drug Policy Consortium, en inglés) del International Drug Policy Consortium; recopilan, sistematizan y analizan información que permite contradecir la versión oficial sobre los niveles de efectividad de la Política.

Ahora, si se habla de disminución en el número de asesinatos, las cifras son también confusas. Las cifras de diferentes ONG con presencia en Colombia demuestran que hay graves errores en el cálculo de este tipo de indicadores - por no mencionar las denuncias en cuanto a ejecuciones extrajudiciales e irrespeto a los derechos humanos- (International Crisis Group, 2009).

Como se ve, la diferencia de resultados no es producto de otra cosa sino del manejo discursivo y el uso del lenguaje, o de otra forma, de la justificación, propósito y alcance de cada una de las políticas. Para ser más explícitos, mientras lo que en Colombia se ve como importante es la caída en el número de secuestros y de tomas de pueblos, y la percepción de seguridad, en EUA lo que importa es la disminución en el número de hectáreas de droga cultivada, y más allá de eso, el descenso en la cantidad de droga circulante en ese país, y en los precios de esta.

En relación con los resultados, es válido recordar que "hay quienes sugieren que los más de 4.200 millones de dólares invertidos por Estados Unidos en la iniciativa no han logrado disminuir la cantidad de droga que sale desde Colombia. A pesar de que efectivamente existen menos áreas de cultivo, gracias a las fumigaciones, los narcos colombianos siguen exportando la misma cantidad de cocaína, lo cual indicaría un aumento de su productividad" (www.talkingdrugs.org). 
Además, que como afirmó el New York Times: "el último capítulo en la larga lucha estadounidense contra las drogas -un esfuerzo de seis años, por US\$ 4,7 billones para rebajar drásticamente los cultivos de coca- ha dejado en precio, calidad y disponibilidad de la cocaína en las calles estadounidenses virtualmente inalterados". (Forero, 2006). Estas posturas diametralmente opuestas -por un lado, la colombiana, que argumenta que el Plan Colombia ha sido un éxito rotundo, y por otro, la americana, que da cuenta de lo contrario- llevan a que se pregunte cuál de ellas encarna mayor veracidad.

Aunque la respuesta no es absoluta, definitivamente tiene que ver con los objetivos que tuvieron tanto el Plan Colombia como la Política de Seguridad Democrática: todos alrededor de la lucha contra las drogas; así, la postura americana está mejor sustentada, por lo menos, en cuanto a que el Plan o la Política no han sido exitosos, simplemente porque no han logrado su objetivo más importante.

\section{La securitización como elemento aglutinador}

Con el marco descrito anteriormente se observa la influencia de las doctrinas norteamericanas en las políticas colombianas, al reairmar el respice polum como la tendencia preponderante en la política exterior de los presidentes Pastrana y Uribe (Cardona, citado por Borda y Tickner, 2011). Sin embargo y al tomar esta realidad particular como antecedente, debe justificacarse que efectivamente para la aplicación/implementación de la securitización como discurso preponderante en el caso de estudio, cada uno de los hechos llama la atención sobre su influencia. Como antecedente y para iniciar la definición del componente teórico que se formula, se debe aclarar que para hacerlo deben abordarse primero, los precedentes del componente, encarnados por la teoría realista y constructivista.

Por su parte, la teoría realista de las relaciones internacionales considera como únicos actores internacionales a los Estados, concibe 
sus relaciones como anárquicas y guiadas únicamente por su deseo por alcanzar el poder, y tiene como a sus más importantes exponentes a Maquiavelo y Hobbes, y más recientemente a Morgenthau y Waltz. Esta teoría privilegia el uso de la fuerza y aboga por el pragmatismo en el uso del poder, al tiempo que concibe como uno de sus elementos claves, el interés nacional, identificado con la seguridad del Estado (Salomón, 2002, p. 9-10).

Es esta una teoría que, por tanto, resulta esencial al analizar las acciones de los Estados Unidos de América, pues se relaciona perfectamente con su pragmatismo y pesimismo al ver las relaciones internacionales, y sobretodo, con la securitización que introducen en otros Estados, igualmente reflejo de su naturaleza realista. De hecho, no es gratuito que los más destacados ejemplos de esta lógica sean importantes diplomáticos estadounidenses, entre ellos Henry Kissinger y George Kennan (Snyder, 2004, p. 53). De esta forma, la teoría realista permite la adecuada contextualización de las relaciones colombo-estadounidenses -en cuanto a seguridad se refiere- durante el periodo que se estudia, y más allá de eso, el entendimiento del significado que ambos gobiernos dan a conceptos como seguridad, seguridad nacional, defensa, amenaza, riesgo, etc. De hecho, gracias a ella se explica que los dos gobiernos ${ }^{4}$ vean en el narcotráfico una amenaza y un riesgo, y, además, lo presenten como el origen de todos los problemas sociales que atraviesa Colombia.

Además, es gracias al realismo que se entiende el porqué de la securitización de las agendas internas y externas de Estados Unidos de América y Colombia, y el atrás descrito interés por hacer girar alrededor de la seguridad todos los elementos de la sociedad -social, económico, cultural, político, etc.-. Es importante decir que se sostiene la idea en la que la teoría realista está insertada dentro de la constructivista, esta a su vez, dentro de la securitización, y, por

4 Andrés Pastrana y Álvaro Uribe, respectivamente. 
último, todas ellas dentro del realismo post-estructural. Por eso, se está de acuerdo en que las raíces de la teoría de la securitización, tal como afirman sus detractores, son completamente realistas (Aradau, 2004, p. 388-413).

Habiendo hecho referencia a la teoría realista, es necesario hacer lo propio con la constructivista. El constructivismo, sea dicho de una vez, se considera el padre de la teoría de la securitización, y contrario al carácter positivista del realismo, da importancia a las ideas que el ser humano tiene sobre la realidad que lo rodea. Por eso, afirma que la seguridad internacional, por ejemplo, es "producto de un conjunto de prácticas sociales y políticas” (Tickner, 2008), que determinan su conceptualización y significado.

Sin duda alguna, el autor que debe nombrarse al hacer referencia al constructivismo y la seguridad, es Peter Katzenstein (1996), quien ha discutido ampliamente el tema, y sostiene que ni el realismo ni el liberalismo han logrado abordar los desafíos que la seguridad nacional e internacional deben enfrentar hoy, pues no tienen en cuenta que los intereses de seguridad de los Estados obedecen a actores que responden a factores culturales.

Lo interesante de Katzenstein (1996), es, sin embargo, que no desvirtúa la importancia que tiene la teoría realista, pues, por el contrario, cree que ella da aportes sustanciales al abordaje de los dilemas de la seguridad, y en general, de los problemas que hoy se quieren ver como amenazas o riesgos para la seguridad internacional. En efecto, en uno de sus artículos, Katzenstein (1996) acepta que los Estados Unidos de América son portadores de un gran excepcionalismo, que determina sus relaciones exteriores, en lo que respecta a su concepción de la seguridad, y que, por tanto, un estudio concienzudo de sus actuaciones, debe tener un carácter integral, multidisciplinar e inclusivo. Por tanto, el análisis de las relaciones colomboestadounidenses, debe hacerse siempre dentro del carácter propuesto 
por este autor, es decir, entendiendo que la política estadounidense es única, y que, por tanto, la colombiana -directamente influenciada por la americana- es igualmente excepcional.

Antes de pasar al estudio de la teoría de la securitización, respecto al constructivismo, Cueva plantea que:

(...) para los constructivistas la defensa no es igual a la seguridad, por cuanto la seguridad siempre fue construida en base al Estado y su derecho territorial y el medio para esto es el ejército (sector militar). Es decir que todo puede ser visto como un tema de seguridad al interior del Estado, pero no puede ser tratado por el sector militar como seguridad del Estado, por tal razón se inicia el proceso de securitización (Cueva, C. 2006).

Respecto a la teoría de la securitización y aunque muchos concuerdan con que fue creada por Barry Buzan y Ole Weaver, el único autor reconocido para esta teoría es el último. Esta es explicada ampliamente por Buzan, Weaver y de Wilde en su libro Security: A New Framework of Analysis, como una versión extrema de la politización, que busca legitimar el uso de medios extraordinarios, pero sobretodo, como una nueva aproximación a la seguridad.

Dentro de esa nueva aproximación se entiende a la seguridad como un proceso que se construye por parte de un actor de acuerdo a su intención. De hecho, el objeto de los estudios de la securitización es entender quién securitiza (el actor securitizador), bajo qué pretexto lo hace (objeto referente), para quién lo hace (la audiencia), y bajo qué condiciones lo hace (Buzan, B. 1998, p. 23-26). Establece que la seguridad es un acto de habla, de intención, de discurso; y de esta forma, por ejemplo, se explica la influencia de la política de securitización americana en la colombiana.

Vale la pena, entonces, en este punto, relacionar los elementos discursivos identificados con el objeto referente, el actor securitizador y el comportamiento de la audiencia - principales unidades de la teoría de la securitización- con las políticas de seguridad de Colom- 
bia y Estados Unidos de América entre 1998 y 2006, pues se verá que todos son exactamente iguales, -incluso el comportamiento de la audiencia, sin importar sus orígenes culturales o sus costumbres distintas-, y que el único cambio se registra en el discurso. Esto será explicado a continuación.

Tanto Clinton como Pastrana usaban el mismo referente para defender el Plan Colombia -la necesidad de llevar desarrollo económico y progreso al país-. Más allá de eso, si se analiza con cuidado, ese referente siguió siendo el mismo con el presidente Bush, hasta los atentados del 11 de septiembre. También es evidente que ese cambio de referente, como consecuencia de los atentados del 11 de septiembre, fue experimentado no sólo por Bush, sino por el presidente Pastrana, quien -también como ya ha sido visto, en las afirmaciones de Tickner- respondió gradualmente al nuevo referente propuesto por George W. Bush.

Uribe haría lo propio, es decir, continuaría apoyando el cambio de referente. Así, la negación de la existencia de un conflicto armado, la afirmación de que ha habido una amenaza terrorista en el país, y la intención de reducir todo ámbito de la sociedad a la esfera de la seguridad -O "seguridad democrática", como él la bautizó- van en perfecta concordancia con el referente propuesto desde los Estados Unidos de América.

Ha quedado claro por qué se afirma que los actores securitizadores y los referentes han sido los mismos; es importante, sin embargo, aclarar por qué se dice que los comportamientos de las audiencias también son iguales, y por qué se acota que los discursos sí varían. El argumento más importante para afirmar que los comportamientos de las audiencias son iguales, se encuentra en las propias reacciones que experimentaron esas audiencias ante políticas tan similares, o de otra forma, ante referentes iguales. Así, tanto para los estadounidenses como los colombianos pasó inadvertido 
que Clinton, Bush, Pastrana y Uribe usaban los mismos referentes, $y$, por tanto, no identificaron que, aunque sus discursos cambiaban, sus referentes (es decir, la libertad, la democracia, la seguridad, etc.) seguían intactos.

Antes de tocar el tema de los discursos, conviene traer a colación lo dicho por Buzan (1998) referente al papel que juegan las audiencias. Al respecto, afirma:

Un discurso que toma la forma de presentar algo como una amenaza existencial a un objeto referente no crea por si misma securitización- que es un avance securitizador, sino el aspecto es securitizado solamente entonces y cuando la audiencia lo acepta como tal. Aceptar no necesariamente significa en términos de civilidad, un discurso libre de dominancia; no significa solamente que un orden siempre descansa en la coerción tanto como en el consenso. Como la securitización nunca puede ser únicamente impuesta, se requiere en algún sentido el ponerse en el caso de uno. (Buzan, 1998, p. 26).

En cuanto a la diferencia de los discursos, esto se argumenta en la cita anterior de Buzan, pues precisamente por ese cambio, fue difícil para las audiencias entender que los objetos referentes eran los mismos; de otro modo, si no hubiera sido por ese cambio, los ciudadanos fácilmente hubieran entendido que los objetos referentes, aunque disfrazados por discursos retóricos y confusos, eran iguales.

Siguiendo por esta línea argumental -la que provee la teoría de la securitización-, es esencial rescatar que lo dicho acá, referente a lo actos discursivos, está apoyado por una de las defensoras más fervientes de la teoría de la securitización, Rita Taureck (2006), quien identifica que el principal argumento de la securitización es que la seguridad es un acto discursivo (speech act), de tal forma que sólo si se relaciona algo con la seguridad, esto merece atención.

De otro modo, explica Weaver,

La securitización se lleva a cabo cuando un actor securitizador (securitizing actor) usa una amenaza contra la existencia de un objeto referente particular (particular referent object), para invocar el derecho a aplicar medidas ex- 
traordinarias para asegurar su sobrevivencia, y más que eso, cuando mueve este asunto fuera de la esfera normal de la política, llevándolo hacia la de la política de emergencia, donde puede ser abordado sin las reglas que una democracia impone (Weaver, 1995, p. 51).

Hay que recordar, igualmente, que, en el marco de los estados de excepción, específicamente en el declarado por Pastrana en 2001, se utilizó un acto discursivo muy especial, por medio de la creación del poder nacional, lo que encaja perfectamente con el uso de los referentes, actores, y audiencias, del modelo de la teoría de la securitización. Esto será explicado con mayor cuidado a continuación, aprovechando las apreciaciones hechas por Rita Taureck (2006).

Así, tal como lo explica Taureck (2006), se usó la expresión 'poder nacional' en razón a que la seguridad ya no tiene un significado dado, sino que responde a lo que el actor securitizador considera como tal; por tanto, la seguridad es una construcción intersubjetiva y social, que, en este caso, respondía al afán del gobierno por declarar como referente amenazado, la democracia y el Estado de derecho colombiano, una vez fueron rotos los diálogos de paz.

Así pues, expresiones similares podrían mencionarse tanto en los gobiernos de Uribe como de Bush y Clinton. El primero, mediante el uso de expresiones como 'amenaza terrorista', 'narcoterrorismo' y 'Estado de derecho'; el segundo, por medio del uso de expresiones como 'eje del mal', o 'la guerra contra el terror'; y el tercero, acudiendo a la defensa de 'la libertad', 'la democracia', y 'el desarrollo económico’.

En este sentido, es básico mencionar el trabajo de Holger Stritzel (2006), pues examina con profundidad cómo las teorías de Escuela de Copenhague -creadora de la teoría de la securitización- pueden aplicarse a la internacionalización de imágenes de 'amenazas', y por tanto, provee un marco de entendimiento perfecto para deducir la influencia que los Estados Unidos de América tuvieron sobre Co- 
lombia; más allá de eso, ya que brinda novedosos desarrollos relacionados con la importancia que tiene 'la internacionalización de las securitizaciones' y el 'rol de las imágenes'.

Como se puede ver, todos estos gobiernos básicamente recurrieron a una securitización exitosa, sustentada perfectamente en los tres pasos definidos hace treinta años por Buzan, Waever y De Wilde (1998): “(1) identificación de amenazas existentes; (2) acción de emergencia; y (3) efectos sobre relaciones inter-unitarias, llevados a cabo por el rompimiento de normas". Se ha aclarado el alcance de la teoría de la securitización, y con ello, ha quedado manifiesto el porqué esta teoría es el argumento más importante para confirmar que la lógica securitizadora estadounidense tuvo una enorme influencia sobre la definición de las políticas de seguridad nacional colombianas entre los gobiernos de Pastrana y Uribe, a tal punto que las del segundo gobierno fueron la continuación de las del primero. Así es evidente que la seguridad es un acto completamente discursivo, cuyo fondo puede permanecer inalterado, mientras su forma se amolda a las características del entorno, o a las exigencias del contexto nacional o internacional.

Ahora, respecto a la segunda línea argumental; la teoría realista post-estructuralista, es pertinente definir qué es el realismo post-estructuralista, y luego explicar por qué compone él la segunda línea argumental de este trabajo. El primero en denominarse un realista post-estructuralista fue Ole Waever (1998), creador de la teoría de la securitización; sin embargo, más recientemente, se han hecho esfuerzos por caracterizar esta teoría, por parte de diferentes académicos. Uno de ellos, Rita Taureck (2006), opina que el realismo post-estructural debe entenderse como una teoría ligada a las diversas raíces de la teoría de la securitización, en cuanto no es más que la aproximación metodológica que está detrás de esa. 
Como se habla de raíces de la teoría de la securitización, conviene hablar de ellas, así sea brevemente, no sólo porque esto ayudará a tener un mejor entendimiento de esta teoría, sino porque permitirá, sin duda alguna, entender que es esta la más apropiada para entender la influencia que tuvo la securitización estadounidense sobre la creación de políticas de seguridad durante los gobiernos de Andrés Pastrana Arango y Álvaro Uribe Vélez (entre 1998 y 2006). Así las cosas, se debe empezar por decir que el realismo post-estructuralista tiene sus raíces en los trabajos desarrollados por John L. Austin, Jacques Derrida, Carl Schmitt y Kenneth Waltz. Como lo afirma Taureck:

"serves as a basis from which to analyse and explain the concept of poststructural realism (Wrver's self description), and importantly as the means - theoretically - by which securitisation theory becomes methodologically possible" (Taureck, 2006, p. 1)

De las afirmaciones de Taureck (2006), es importante resaltar el énfasis que hace en la relación existente entre la teoría de la securitización y el realismo post-estructural, pues eso posibilitará entender que ambos tienen raíces comunes, y más allá de eso, que entendiendo las de cualquiera de ellos, inexorablemente se podrán comprender las del otro.

Respecto a la influencia de los autores mencionados, el primero de ellos, John L. Austin (1962), es el creador de los actos discursivos (speech acts, en inglés), y, por tanto, su influencia sobre Waever es más que obvia. De hecho, es en él en quien este se apoya para crear la mayor parte de su teoría de la securitización. El siguiente autor que jugó un rol importante sobre la creación de las teorías de Waever es Waltz, pues según el propio Waever, Waltz cambió la cara de las Relaciones Internacionales, porque gracias al neorrealismo según Waever:

"realism was reformulated in a systematic and minimalist way, where previous broad speculations were replaced by a precise argument. The resulting theory was theory to a previously unknown degree of theory" (Waever, 2004, p. 4). 
Como se ve, las raíces de las teorías de Waever, lejos de ser pertenecientes a una única corriente de pensamiento, son bastante disímiles; esto, lo único que demuestra es la intención del autor por proponer enfoques integracionistas y multidisciplinarios que sirvan para abordar fenómenos que requieren de un análisis -que, entre otros, es similar al que proponen las relaciones internacionales- en el que diversos sectores sean integrados, y varias perspectivas sean evaluadas.

Lo anterior puede ser constatado por lo que afirma Taureck, quien entiende la teoría del realismo post-estructural como "una aproximación al estudio de las relaciones internacionales informado por el objetivo de estudiar la construcción política y social de la seguridad con métodos post-estructurales, mientras se hacen concesiones a los conceptos realistas, tratándoseles como constructivistas” (Taureck, 2006, p. 4). Continua Taureck (2006)

"an approach to the study of IR informed by the objective to study the social and political construction of security with post-structural methods, whilst making allowances for realist concepts, and treating them as constructed givens. An approach, so it will be argued that resembles much of mainstream moderate constructivism, in that both - mainstream constructivism and poststructural realism - sit somewhere halfway between mainstream IR theory (the inter paradigm debate) and post-structuralism” (p. 5).

A propósito del post-estructuralismo, conviene traer a colación al post-estructuralista Jeff Huysmans (2002), quien al hablar de los dilemas normativos de la seguridad y la securitización, pone sobre la mesa, como ya ha sido explicado, uno de los más importantes elementos de la securitización: el uso del lenguaje, factor que es, "no sólo un instrumento comunicativo usado para hablar sobre un mundo real fuera del lenguaje, sino uno que opera como instrumento mediador que incluye a las prácticas sociales dentro de un marco comunicativo e institucionalizado particular” (Huysmans, 2002, p. 44). Para un mejor entendimiento, Catherine Charret (2009) anota 
que, al hablar del lenguaje, Huysmans (2002) se refiere al poder simbólico de la seguridad, como palabra y concepto, que puede ser entendida como una tecnología política (Charret, 2009, p. 13-15).

Como se ve, dentro de la teoría post-estructuralista también tiene una gran relevancia el uso del lenguaje, por lo que es mucho más fácil entender el porqué acuñó Waever a su teoría el calificativo de post-estructural. Se reitera, en este punto, que no es de ninguna manera coincidencial que el realismo post-estructural sea presentado como una teoría tan integradora por Waever, pues es ese carácter integrador el que lo hace tan válido y esencial. Un carácter que representa no sólo el uso de símbolos y objetos referentes, sino del lenguaje, como elemento articulador de las prácticas sociales, o de otro modo, de los actos discursivos.

Ahora, respecto al papel del realismo post-estructural como segunda línea argumental de este artículo; la influencia que tuvieron los estadounidenses sobre las políticas colombianas de seguridad ha sido enorme, pues como ya ha quedado también demostrado, las políticas de seguridad de Pastrana y Uribe han estado perfectamente alienadas con las de Clinton y Bush; la línea argumental anterior mostró cómo el uso del discurso ha sido esencial para dejar clara esta influencia, y más allá de eso, cómo la teoría de la securitización es reflejo perfecto de eso.

Sin embargo, no ha quedado claro bajo qué óptica debe analizarse toda esta situación, pues definitivamente la teoría mencionada es hasta cierto punto reduccionista, pues a juicio de muchos, rechaza el realismo, teoría que explica perfectamente el fondo del asunto abordado. Esa óptica es la del realismo post-estructural, pues él brinda una opción válida a ese problema reduccionista, en tanto, como ya se ha visto, parte de que tanto el realismo, el constructivismo, como la teoría de la securitización son importantes, y todos constituyen marcos de referencia bajo los cuales tiene que analizarse 
cualquier situación o problema de las relaciones internacionales o los estudios políticos.

Pero ese afán por emprender estudios de seguridad no es sólo interés de este artículo; al contrario, bajo marcos amplios e interdisciplinarios es que Arlene Tickner ha desarrollado sus últimos escritos, haciendo un análisis bajo el marco de la teoría de la securitización y planteando la necesidad de emprender estudios comparativos, incluyentes y transdisciplinares. Y es que Tickner hace contribuciones importantes porque no sólo analiza la acción securitizadora en Colombia, sino que brinda soportes teóricos y conceptuales esenciales, al tiempo que hace estudios comparativos regionales al respecto. En efecto, en su ponencia, presentada durante el Primer Congreso de Ciencia Política en el año 2008, la autora hace énfasis en la importancia de considerar dinámicas de seguridad intermésticas, desterritorializadas y operativas, que vayan más allá del conflicto colombiano. De hecho, Tickner (2008) afirma que:

Durante los últimos años la región andina ha sido considerada como el epicentro de la inseguridad del hemisferio occidental. Aunque muchos de los factores que han erosionado la estabilidad de los Andes - entre ellos, la debilidad institucional, la fragilidad de la democracia, la desigualdad social y económica, y la inseguridad ciudadana- operan a nivel nacional, otros aspectos de la crisis de seguridad andina son más de carácter transnacional.

La mayoría de los análisis académicos y políticos sobre este tema, al enfatizar el conflicto colombiano como factor desestabilizador y/o diversos problemas que enfrentan países individuales en la zona, impide la consideración de dinámicas de seguridad que son intermésticas, desterritorializadas y operativas en la región entera o partes significativas de ella.

El trabajo de Barry Buzan y Ole Waever (2003) sobre las regiones y la seguridad, con el que culminan estos autores más de una década de reflexiones sobre las lógicas regionales de seguridad (Buzan 1991; Waever 1995; Buzan, Waever y de Wilde 1998), sugiere que el factor determinante de todo complejo regional de seguridad son las prácticas interrelacionadas de securitización que existen entre los estados miembros, que hacen imposible analizar o resolver sus problemas individuales de seguridad de forma separada. 
Hasta este punto, se han desarrollado las dos líneas argumentales a través de las cuales se abordaba el análisis propuesto; la segunda y última de estas líneas, además, significó la defensa de la idea de que las políticas de seguridad de los gobiernos de los Estados Unidos de América y de Colombia deben estudiarse bajo el marco de referencia que brinda la teoría realista post-estructuralista. Así, tal como lo afirma Nicholas Kitchen (2010): "lo que hace a la teoría realista neoclásica 'nueva' es su intento por sistematizar los amplios y variados entendimientos de los realistas clásicos dentro de una teoría mezquina, o hacer lo contrario, identificar las variables apropiadas que intervienen que pueden imbuir a la variante estructural del realismo con una riqueza explicativa mayor”.

En este sentido, según Kitchen (2010)

"What makes neoclassical realist theory 'new' is its ongoing attempt to systematise the wide and varied insights of classical realists within parsimonious theory, or to put it in reverse, to identify the appropriate intervening variables that can imbue realism's structural variant with a greater explanatory richness. In this sense, 'post-structural realism' could be as apt a designation for this area of IR that values theory and seeks at least some kind of predictive capacity, while at the same time recognising that the world is complex, and that events in international politics reflect the interaction of multifarious factors" (p. 117-143).

Como se ve, es aceptado que ese realismo post-estructural brinda muchas respuestas a diversas situaciones políticas mundiales, porque considera la interacción de factores múltiples, y de ese modo, puede llegar a tener una capacidad predictiva importante; aun más, tiene la ventaja de ofrecer marcos de referencias que, sin complejizar excesivamente los eventos, acepte que en ellos interactúan diversas variables, y que todas ellas son igualmente importantes.

Por otra parte, lo que hace el realismo post-estructural es proponer al analista un modelo que aboga por volver a la simpleza de los problemas políticos, aceptando la relevancia y complejidad que 
esa simpleza puede representar. Entonces, esta teoría -la realista post-estructuralista- efectivamente es la adecuada para analizar la securitización de políticas que indujo Estados Unidos de América en Colombia, simplemente porque es capaz de analizar diversos factores: geopolíticos, sociales, culturales, del lenguaje, etc., que tienen un peso muy importante en una situación como la colombiana y en una relación como la colombo-estadounidense.

$\mathrm{Y}$ es que en la situación colombiana y americana, y en la relación bilateral que ellos mantienen, es tan esencial el factor económico y geopolítico, representado por la importancia de Colombia como vecino de un proveedor de petróleo importante y los recursos naturales que posee, como el del lenguaje y el cultural, encarnado en los imaginarios colectivos, la legitimidad de la clase dirigente y de las políticas del gobierno de turno, porque son estos últimos, los que finalmente, hacen posible que se produzcan comportamientos deseados o no, por parte de la población.

\section{Conclusión}

Por lo anterior, se pueden determinar dos conclusiones referentes a las líneas argumentativas que desarrolló este artículo. En primer lugar, la teoría de la securitización, desarrollada en el seno de la Escuela de Copenhague, y que afirma que la seguridad realmente es un acto discursivo que depende de tres elementos fundamentales: un objeto referente, una audiencia y un actor securitizado, fundamenta teóricamente el argumento de que tanto la seguridad en los Estados Unidos de América como en Colombia eran tan sólo un acto discursivo, que además de haber estado coordinado, había dado resultados similares, aun cuando sus audiencias habían sido claramente diferentes, y los objetos referentes, no exactamente iguales.

Por su parte, la segunda línea argumental, giró en torno a la presentación, descripción y análisis de la teoría realista post-estruc- 
turalista, a la que se propuso como marco de referencia obligado para el estudio de la securitización inducida por los Estados Unidos de América sobre las políticas de seguridad desarrolladas en Colombia en el lapso estudiado. Al respecto, se mostró que la teoría mencionada posibilitaba entender por qué, si bien había un claro trasfondo realista en las actuaciones americanas y colombianas en materia de seguridad, era igualmente importante el componente del lenguaje, es decir, el componente social y cultural que el realismo deja de lado, por considerarlo poco relevante.

Por otro lado, el elemento discursivo jugó un papel preponderante para la legitimación de esos gobiernos y sus políticas, quienes gracias a él lograron tener una aceptación importante; pero más allá de eso, es la teoría realista post-estructuralista el marco bajo el cual debe analizarse cualquier evento de la política nacional (ella representa la única forma de entender la transición política colombiana en el periodo tomado en consideración, pues por medio suyo se puede entender que el primer término de Uribe sólo encarnó un proceso de evolución -no de revolución- que empezó con el "pacifista" presidente Pastrana) e internacional, pues ella propone un enfoque multidisciplinar, integrador y no reduccionista, igual a la naturaleza propia de las Relaciones Internacionales.

Ese elemento discursivo, permite ratificar el argumento central de este artículo, el cual pretendió demostrar que los gobiernos de Uribe y Pastrana, en Colombia, y de Clinton y George W. Bush, en EUA, encarnan una continuidad importante, evidenciada en sus preceptos principales, las metas que perseguían, sus resultados y sus líneas de acción y por tanto, debido a la tendencia colombiana de alinearse a su aliado del norte, las políticas exteriores de Clinton y Bush en materia de seguridad, influenciaron las políticas de seguridad que desarrollaron los gobiernos de Pastrana; al buscar por medio del Plan Colombia la desarticulación de las guerrillas, la consecución de 
la paz y el impulso económico y de Uribe, con el desarrollo de su política de Seguridad Democrática, mediante la cual conseguía beneficios en todas las materias a través de la garantía de la seguridad militar.

\section{Bibliografía}

Aradau, C. (2004). Security and the Democratic Scene: Desecuritization and Emancipation, Journal of International Relations and Development 7.

Austin, J. (1962). How to do things with words: The William James Lectures delivered at Harvard University in 1955. Ed. J. 0. Urmson. Oxford: Clarendon.

Badey, T (2006). U.S. Counterterrorism: Change in Approach, Continuity in Policy. Contemporary Security Policy 27.

BBC, $(08,30,2000)$. A qué juega Pastrana. bbcmundo.com

Buzan, B.; Waever, 0.; y De Wilde, J. (1998). Security: A New Framework of Analysis. Lynne Rienner Publishers.

Cardona, D (citado por Borda y Tickner, 2011), La política exterior de la administración Pastrana (1998-2002) hacia una evaluación preliminar, en Relaciones Internacionales y Política Exterior Colombiana, Ediciones Uniandes, tomado de https://appsciso. uniandes.edu.co/sip/data/pdf/relacionesinternacionales4.pdf

Caro, 0 (2006), La doctrina Bush de la guerra preventiva: ¿Evolución del "ius ad bellum” 0 vuelta al Medioevo?, Revista Facultad de Derecho y Ciencias Políticas, Vol $36 \mathrm{n}^{0} 105$, tomado de http://www.redalyc.org/pdf/1514/151413539008.pdf

Carrigan, A. (08, 23, 2000). Clinton's Plan Colombia: Disturbing Questions Concerning The Real US Agenda. The Irish Times.

Carvajal, Jorge (2008). La Seguridad dentro del Estado de Garantías. Bogotá: Instituto Latinoamericano de Servicios Legales Alternativos.

Charrett, C. (2009). A Critical Application of Securitization Theory. Institut Catala Internacional per la Pau.

CNN $(06,23,2004)$. Clinton defends succesor's push for war. 
Cueva, C. (2004-2006). Securitización y construcción de percepciones: el Plan Colombia y la seguridad humana. Tesis Inédita de Maestría. Programa de Maestría en Relaciones Internacionales. Facultad Latinoamericana de Ciencias Sociales Sede Ecuador.

Davidson, L. (2005). Christian Zionism as a Representation of American Manifest Destiny. Critique: Critical Middle Eastern Studies 14(2).

Forero, J. $(08,19,2006)$. Colombia's Coca Survives U.S. Plan to Uproot It. The New York Times.

GA0 (2005). Report to Congressional Requesters. Drug Control: Air Bridge Denial Program in Colombia has implemented new safeguards, but its effect on drug trafficking is not clear.

GAO (2008). Report to the Honorable Joseph Biden. Plan Colombia. Drug Reduction Goals were not fully met, but Security has improved.

Guida, M (2010), La política exterior neoconservadora de Estados Unidos, cambios, continuidades y perspectivas, Revista CIDOB d'Afers Internacionals, num 91, tomado de file:/// Users/natarubioc/Downloads/9_MARIAN0\%20ANDRES\%20GUIDA.pdf

Hendrickson, Ryan (2008). Clinton, Bush, Congress and War Powers: A comparative Analysis of the Military Strikes on Iraq and Bin Laden. Recuperado de http://www.wilsoncenter.org/events/ docs/hendrickson.pdf

Huysmans, J. (2002) Defining Social Constructivism in Security Studies: The Normative Dilemma of Writing Security. Alternatives 27: Special Issue. 2002.

Instituto de Ciencia Política Hernán Echavarría Olózaga (2009). Financiamiento del gasto militar en Colombia en Observatorio Legislativo Vol. 138.

International Crisis Group (2008). Colombia: Making Military Progress Pay Off, Latin America Briefing Vol. 18.

International Crisis Group (2009). The Virtuous Twins: Protecting Human Rights and Improving Security in Colombia, Latin America Briefing Vol. 21.

Katzenstein, P. (1996). The Culture of National Security. Columbia University Press.

Katzenstein, P. (2002). Same War, different views: Germany, Japan, and the War on Terrorism Current History. Philadelphia: Dec 2002.Vol. 101, Iss. 659.

Kitchen, N. (2010). Systemic pressures and domestic ideas: a neoclassical realist model of grand strategy formation. Review of International Studies. 
La Onda Digital $(12,04,2000)$. Punto de vista de la Comisión de Internacionales de la FA "El Plan Colombia".

Ministerio de Defensa Nacional-Presidencia de la República de Colombia (2004). Efectividad de la política de seguridad democrática agosto 2002-enero 2004.

Moens, A. (2004). The Foreign Policy of George W. Bush: Values, Strategy, and Loyalty. Ashgate.

Pastrana, A. No todo comenzó con Uribe. El Nuevo Siglo. Febrero 23 de 2005.

Pastrana, A. (2010). Retroceder en la memoria es una opción.

Presidencia de la República de Colombia (2000). Plan Colombia.

Presidencia de la República-Ministerio de Defensa Nacional (2003). Política de Defensa y Seguridad Democrática.

Salomón, M. (2002). Teorización de las Relaciones Internacionales. Revista CIDOB d’Afers Internacionals, No. 56, dic.2001/enero 2002.

Schlesinger, A. (02, 27, 2002). La guerra preventiva. El País.

Snyder, J. (2004) One World, Rival Theories. Foreign Policy, November/December.

Stritzel, H. (2006) "Securitisation Theory and the Internationalisation of Threat Images" Paper presented at the annual meeting of the International Studies Association, Town \& Country Resort and Convention Center, San Diego, California, EUA.

Talking Drugs (10, 02, 2009). Bill Clinton destaca éxito del Plan Colombia. Recuperado de http://www.talkingdrugs.org/es/bill-clinton-destaca-\%C3\%a9xito-de-plancolombia

Taureck, R. (2006) Securitisation Theory and Securitisation Studies. Journal of International Relations and Development.

Taureck, R. (2006). Securitisation Theory - The Story so far: Theoretical Inheritance and what it means to be a post-structural realist. Paper para ser presentado en la cuarta Convención Anual de CEEISA, University of Tartu, 25-27 de junio de 2006.

The White House (1998). Presidential Decision Directive PDD 2 "Organization of the National Security Council". 
Tickner, A. Los Estados y la securitización: dinámicas de seguridad andina. Ponencia presentada al primer congreso de ciencia política. Universidad de los Andes. Septiembre 30 a octubre 4 de 2008.

Tiusabá, Beatriz (2004). Política de Defensa y Seguridad Democrática: Evolución, Desarrollo e Implementación. Tesis Inédita de Pregrado. Universidad de Los Andes, Bogotá, Colombia.

Tokatlian, J. (2004). Colombia U.S. Security Policy in the Andean Region and the Specter of a Regionalized War en Strategy for Empire. En Brian Loveman (Ed.). EUA: SR Books.

Veillete, C. (2005). Plan Colombia: A Progress Report. Washington: CRS Report for Congress.

Waever, 0. (1995). Securitization and Desecuritization. In On Security, ed. Ronnie Lipschutz. NY: Columbia University Press. 1995.

Waever, 0. (2004). The Ten Works. Tidsskriftet Politik Vol.7:4.

Worley, R (2008). The National Security Council: Recommendations for the New President. IBM Center for The Business of Government. 